J U R N A L D I S T R I B U S I|p-ISSN : 0853-9571

Jurnal Ilmu Manajemen dan Bisnis $\mid$ e-ISSN : 2477-1767

Vol. 7, No. 2 - September 2019

Halaman 251 s.d 260

\title{
PENGEMBANGAN JEJARING WIRAUSAHA DALAM MENINGKATKAN KINERJA UNIT USAHA MIKRO KECIL DAN MENENGAH DI KOTA BIMA
}

\author{
Nurul Huda ${ }^{1}$, Sri Syamsinirwani ${ }^{2}$ \\ ${ }^{\text {ISSekolah Tinggi Ilmu Ekonomi Bima, nurulhuda.stiebima@gmail.com }}$
}

\begin{abstract}
ABSTRAK
Penelitian ini bertujuan untuk melihat Apakah Jejaring Wirausaha berpengaruh terhadap kinerja UMKM di Kota Bima, Apakah Pembelajaran Eksploratif berpengaruh terhadap kinerja UMKM di Kota Bima, dan manakah di antara variable

jejaring wirausaha dan Pembelajaran Eksploratif yang memiliki pengaruh dominan terhadap kinerja UMKM di Kota Bima. Penelitian ini dilakukan pada UMKM di Kota Bima Selama 7 (tujuh) bulan. Penelitian ini terbagi dalam beberapa tahapan, yaitu 1) Persiapan (2) Pelaksanaan, (3) Pelaporan, (4) Monitoring, evaluasi, dan diseminasi. Metode penelitian dipakai adalah penelitian explanotory research dengan menggunakan pendekatan survey sampel. Secara konfensional, explanatory research digunakan untuk menjelaskan hubungan antara variabel-variabel dengan melalui pengujian hipotesis. disebarkan Quesioner ke 104 UMKM di Kota Bima, dimana quesioner ini diuji validitas dan reliabilitasnya kemudian diolah menggunakan SPSS sehingga ketepatan alat analisanya bisa reliable. Hasil penelitian menunjukan bahwa Jejaring Wirausaha berpengaruh terhadap kinerja UMKM di Kota Bima sedangkan Pembelajaran Eksplorasi tidak berpengaruh terhadap kinerja UMKM di Kota Bima
\end{abstract}

Kata Kunci: Pembelajaran Eksplorasi. Jejaring Wirausaha, Kinerja UMKM

\section{ABSTRACT}

This study aims to see whether Entrepreneurial Networks influence the performance of Micro Small and Medium Enterprises (UMKM) in the City of Bima Does Explorative Learning affect the performance of Micro Small and Medium Enterprises (UMKM) in Bima City, and which of the entrepreneurial networking variables and Exploratory Learning has a dominant influence on the performance of Micro Small and Medium Enterprises (UMKM) in Bima City. This research was conducted on Micro Small and Medium Enterprises (UMKM) in Bima City for 7 (seven) months. This research is divided into several stages, namely 1) Preparation (2) Implementation, (3) Reporting, (4) Monitoring, evaluation, and dissemination. The research method used is explanatory research research using the sample survey approach. Conventionally, explanatory research is used to explain the relationship between variables by testing hypotheses. Questionnaires were distributed to 104 Micro Small and Medium Enterprises (UMKM) in Bima City, where questionnaires were tested for validity and reliability and then processed using SPSS so that the accuracy of the analysis tools could be reliable. The results showed that. Network Enterpreneur affected the performance of Micro Small and Medium Enterprises (UMKM) in Bima City while exploratory learning did not affect the performance of Micro Small and Medium Enterprises (UMKM) in Bima City.

Keywords: Exploratory Learning, Network Enterpreneur,Micro Small and Medium Enterprises (UMKM) Performance 


\section{PENDAHULUAN}

Usaha Mikro Kecil dan Menengah Di Kota Bima dalam kiprahnya menghadapi permasalahan-permasalah baik internal maupun eksternal sehingga UMKM belum bisa memberikan kontribusi yang optimal seperti halnya lembaga perekonomian lainnya. Salah satu permasalahannya adalah rendahnya kualitas sumber daya manusia sehingga pengelolaanya berdampak pada daya saing dan kemampuan untuk menerobos pangsa Pasar. Kemampuan Usaha Mikro Kecil dan Menengah perlu diberdayakan dan dikembangkan secara terus menerus dengan berusaha mereduksi kendala yang dialami Usaha Mikro Kecil dan Menengah, sehingga mampu memberi kontribusi lebih maksimal terhadap peningkatan kesejahteraan masyarakat.

Dalam pengembangan UMKM ini masih ditemukan permasalahannya, antara lain: lemahnya struktur permodalan dan akses terhadap sumber permodalan, ketersediaan bahan baku dan kontinuitasnya, terbatasnya kemampuan dalam penguasaan teknologi, lemahnya organisasi dan manajemen usaha, dan kurangnya kuantitas dan kualitas sumberdaya manusia. Disini diperlukan jaringan Network kerjasama kemitraan usaha antara Perbankan, Pemerintah, Perguruan Tinggi, Lemlit, Puslit untuk bersama-sama mengadakan perbaikan kualitas dan meningkatkan kinerja UMKM di Kota Bima

Beberapa literatur penelitian juga ditemukan kontradiksi teoritis yaitu adanya research gap, yang menyatakan kapabilitas jejaring memiliki pengaruh positif terhadap kinerja perusahaan ,sedangkan beberapa hasil penelitian yang lain menyatakan bahwa kapabilitas jejaring tidak memiliki pengaruh terhadap kinerja perusahaan (3) Selain itu juga adanya perbedaan pendapat mengenai komponen Pembelajaran Eksploratif ada yang berpengaruh negatif dan positif terhadap kinerja UMKM (5), (1) Jejaring Wirausaha dan Pembelajaran Eksploratif terbukti signifikan berpengaruh positif terhadap Kinerja UMKM (9)

Dengan melihat latar belakang permasalahan diatas maka perlu dicarikan solusi pemecahan atas segala kendala yang masih dialami unit usaha mikro kecil dan menengah, salah satu alternatif pemecahannya adalah perlu dikembangankan pengembangan jejaring wirausaha dan pembelajaran eksploratif yang memegang peranan penting kegiatan pemberdayaan ekonomi masyarakat terutama rakyat kecil dan pelaksana penuh pemasaran produk UMKM, yang akan menghubungkan UMKM dengan pihak yang terkait untuk meningkatan kinerja UMKM dan kesejahteraan masyarakat selanjutnya dengan demikian dirumuskan permasalahan sebagai berikut: (1) Apakah Jejaring wirausaha berpengaruh terhadap kinerja UMKM di Kota Bima, (2) Apakah pembelajaran Eksporatif berpengaruh terhadap Kinerja UMKM di Kota Bima, (3) Manakah diantara variabel Jejaring Wirausaha dan Pembelajaran Eksporatif yang memiliki pengaruh dominan terhadap kinerja UMKM di Kota Bima.

Tujuan jangka panjang yang ingin dicapai adalah peningkatan kinerja UMKM di seluruh Kota Bima dengan adanya jejaring wirausaha. Tujuan khusus yang ingin dicapai adalah peningkatan kinerja UMKM di seluruh Kota Bima dengan penerapan jejaring wirausaha. Target luaran yang akan dicapai dengan jejaring wirausaha untuk UMKM adalah diperoleh suatu model jejaring wirausaha yang akan diterapkan mendukung peningkatan kinerja UMKM yang digambarkan dengan peningkatkan kapasitas belajar lewat pembelajaran eksploratif SDM. Urgensi penelitian diharapkan dapat memberikan peningkatan kinerja UMKM lewat pembelajaran eksploratif SDM, mendorong terjadinya efisiensi penggunaan sumber-sumber, meningkatkan kapasitas perencanaan dan implementasi untuk mengatasi masalah yang rumit, memperbanyak sumber pertumbuhan 
ekonomi, penciptaan lapangan kerja, peningkatan jaringan kerjasama (networking) bekerjasama dengan mitra usaha dan peningkatan daya saing, memberikan pelayanan yang lebih baik kepada klien dan pelanggan dan tidak tergantung kepada produk-produk impor yang melemahkan ketahanan ekonomi rakyat secara keseluruhan.

\section{KAJIAN TEORI}

\section{Jejaring Wirausaha}

Tantangan utama pihak manajer puncak adalah menciptakan suatu lingkungan dimana orang-orang dapat mengeksploitasi informasi dengan cara yang lebih efektif ; dalam hal ini, konsep utamanya adalah jejaring (networking). Jejaring hubungan personal cukup efektif dalam mengkomunikasikan informasi yang kompleks, sinyal-sinyal yang halus dan sensitif, serta transfer pengetahuan Informasi adalah data yang telah memenuhi persyaratan tertentu untuk dijadikan rujukan bagi perusahaan dalam menjalankan kegiatannya (14)

\section{Gambar 1. Peta Jalan Penelitian}

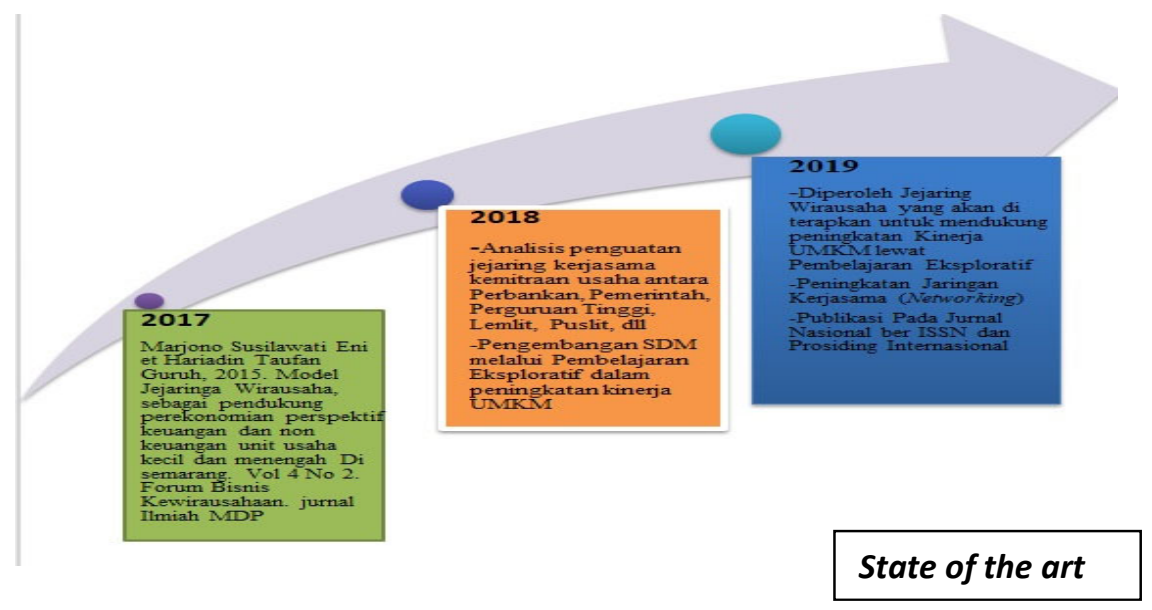

(5) jejaring wirausaha yaitu kewirausahaan yang diasosiakan dengan penciptaan pola-pola jejaring kegiatan ekonomi baru melalui realisasi inovasi yang interaktif atau dengan menjembatani penawaran dan permintaan, atau, yang lebih umum, melalui integrasi bidang-bidang kegiatan yang berbeda. Jejaring wirausaha dapat dikaitkan dengan semua ikatan dalam keseluruhan jejaring personal yang ada dan dipelihara oleh para manajer usaha Mikro kecil dan menengah dalam rangka untuk mengidentifikasi peluang-peluang yang dapat dieksploitasi di masa depan

(6) Jejaring sering didefinisikan sebagai hubungan yang terpola diantara faktorfaktor yang bertindak sebagai individu, kelompok maupun organisasi. Jejaring dapat menggunakan berbagai bentuk antara lain: aliansi stratejik, joint ventures, pengaturan lisensi, subcontracting, kegiatan-kegiatan kerjasama R \& D dan pemasaran

\section{Pengembangan Framework Jejaring}

(7) Pengembangan suatu framework multidimensional yang sesuai dengan sasaransasaran penelitian kewirausahaan diilhami dari kerja Parsons yang menerangkan ada 4 mekanisme yang melekat dalam definisi ini, yaitu: 
a. Interaksi antara pemain

b. Usaha untuk pencapaian sasaran

c. Optimisasi proses, dan

d. Memelihara pola-pola struktur secara budaya dan memberikan symbol-simbol.

Empat Dimensi Pengembangan Framework Jejaring

a. Jangkauan (scope)

b. Skala (scale)

c. Ketrampilan \& Nilai (Skills \& Value)

d. Jejaring Sosial

Sumber (7)

\section{Pembelajaran Eksploratif}

Pembelajaran Eksploratif merupakan kegiatan yang didalamnya mencakup kegiatan pelatihan internal karyawan, berbagi bertukar ketrampilan dan pengetahuan untuk meningkatkan kualitas SDM dan produk. Disini penting sekali adanya kerjasama dengan lembaga pelatihan mitra usaha untuk mengembangkan pengetahuan seperti perusahaan kecil dan besar, lembaga binaan, perguruan tinggi, Lemlit, Puslit untuk saling bertukar pengalaman dan hasil penelitian. Organisasi yang lebih menekankan pada tanggapan (responsiveness) dan pengelolaan penetahuan akan meningkatkan pembelajaran team, dan pada gilirannya, pembelajaran team mempengaruhi kinerja tugas dan kualitas hubungan interpersonal secara positif (13)

\section{Kinerja Perusahaan}

Perusahaan dalam mengukur kinerjanya ada yang berdasarkan perolehan finansial perusahaan, ada juga yang berdasarkan proses wirausaha sampai dapat menghasilkan hasil (outcomes) yang berbeda-beda pada berbagai dimensi baru. Pengukuran kinerja perusahaan kecil dan menengah belum terdefinisikan dengan baik, sehingga dalam beberapa penelitian yang telah dilakukan banyak menggunakan aspek-aspek pengukuran yang tidak penting.

(12) kinerja perusahaan dapat dilihat dari dimensi pertumbuhan dan dihubungkan dengan finansial, yang dapat dikaitkan dengan kinerja perusahaan yang telah lalu. Misalnya pertumbuhan penjualan dan pertumbuhan pasar secara tradisional digunakan untuk mengukur kinerja. Dimensi kedua yaitu mengamati aspek-aspek kejadian kinerja perusahaan saat ini. Ini berkaitan dengan aspek-aspek non-finansial, yang masih vital bagi perusahaan, misalnya aspek kinerja pelanggan.

(15) Kinerja pelanggan disini dimaksudkan apabila pengusaha memiliki basis pelanggan yang puas dan loyal penting bagi perusahaan untuk tetap mempunyai daya saing. Dimensi ketiga dilihat sebagai indikator kinerja perusahaan yang berorientasi masa depan, misalya aspek- aspek inovasi perusahaan. Dengan bertindak inovatif akan mengarah pada keunggulan kompetitif dimana indikator-indikator inovasi melibatkan pertanyaan-pertanyaan yang berkaitan dengan kemampuan perusahaan untuk mengembangkan produk, proses atau jasa baru. 


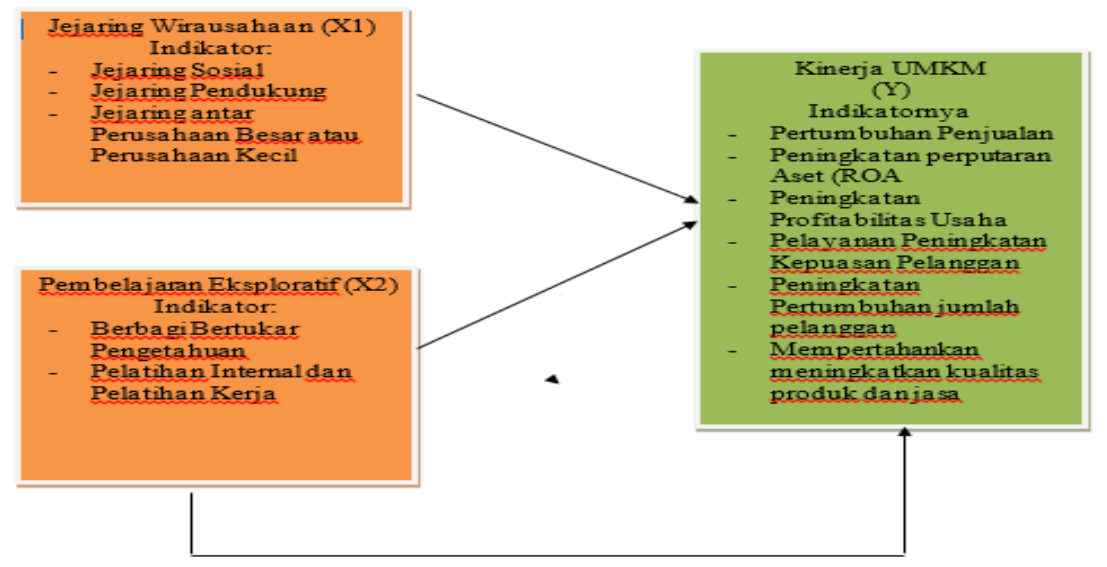

Hipotesis penelitian adalah sebagai berikut:

H1 : Jejaring Wirausaha berpengaruh terhadap kinerja UMKM di wilayah Kota Bima.

H2 : Pembelajaran Ekplorasi berpengaruh tehadap kinerja UMKM di wilayah Kota Bima.

H3 : Jejaring Wirausaha dan Pembelajaran Ekplorasi yang berpengaruh dominan terhadap peningkatkan kinerja UMKM di wilayah Kota Bima

\section{METODOLOGI PENELITIAN}

Jenis penelitian yang digunakan pada penelitian ini penelitian kuantitatif dengan Metode penelitian dipakai adalah penelitian explanotory research dengan menggunakan pendekatan survey sampel. Secara konfensional, explanatory research digunakan untuk menjelaskan hubungan antara variabel-variabel dengan melalui pengujian hipotesis. data kuantitatif dengan digunakan pendekatan survei yaitu Penelitian yang dilakukan dengan menggunakan qusioner sebagai alat penelitian yang dilakukan pada populasi besar maupun kecil, tetapi data yang dipelajari adalah data dari sampel yang diambil dari populasi tersebut, sehingga ditemukan kejadian relatif, distribusi, dan hubungan antar variabel, sosiologis maupun psikologis (11). Penelitan ini dilakukan di Kota Bima dengan populasi adalah keseluruhan UMKM dari berbagai sector ekonomi yang ada di wilayah Kota bima. Jumlah UMKM yang ada di wilayah kota bima Menurut (2) karena jumlah UMKM yang ada di wilayah kota Bima sangat banyak, dan tidak mungkin meneliti semua karena banyak keterbatasan, maka jumlah sampel yang digunakan adalah sebanyak 104 responden, supaya data responden lebih mewakili dari populasi. Teknik pengambilan sampel dengan Purposive sampling yaitu dengan cara menetapkan ciri-ciri khusus yang sesuai dengan tujuan penelitian sehingga diharapkan dapat menjawab permasalahan penelitian

Teknik pengumpulan data yang digunakan dalam penelitian ini, yaitu (a) Qusioner, (b) Observasi, (c) Study pustaka. Variabel dalam penelitian ini adalah Jejaring Kewirausahaan variabel independent (X1), Pembelajaran Eksporatif Variabel Independen (X2) dan Kinerja UMKM sebagai variabel dependent (Y) dengan beberapa indikator sebagai tolak ukur untuk melihat pengaruh antara variabel $\mathrm{X}$ dan variabel $\mathrm{Y}$. Pengukuran variabel menggunakan skala likers. Skala likert digunakan untuk mengukur 
sikap, pendapat, dan persepsi seseorang atau sekelompok orang tentang fenomena sosial (10). Dalam memberikan pembobotan pada masing-masing variabel diberikan pilihan jawaban Sangat Setuju (SS) yang diberi skor 5, Setuju (S) yang diberi skor 4, Netral (N) yang diberi skor 3, Tidak Setuju (TS) yang diberi skor 2, dan Sangat Tidak Setuju (STS) yang diberi skor 1. Tekniik analisis data menggunakan regresi linier berganda dengan menggunakan alat analisis SPSS.

\section{HASIL DAN PEMBAHASAN}

\section{Uji Validitas}

Tabel 1. Hasil Uji Validitas

\begin{tabular}{|c|c|c|c|}
\hline r. Hitung Variabel X & r. Hitung Variabel Y & r. Tabel & Keterangan \\
\hline (X1.item 1) 0,699 & (Y.item 1) 0,626 & 0,300 & Valid \\
\hline (X1.item 2) 0,837 & (Y. item 2) 0,656 & 0,300 & Valid \\
\hline (X2.item 3) 0,841 & (Y. item 3) 0,629 & 0,300 & Valid \\
\hline (X2.item 4) 0,905 & (Y.item 4) 0,605 & 0,300 & Valid \\
\hline (X2.Item 5) 0,916 & (Y.item 5) 0,708 & 0,300 & Valid \\
\hline & (Y.item 6) 0,661 & 0,300 & Valid \\
\hline
\end{tabular}

Sumber : Data diolah 2019

Berdasarkan tabel 1 dapat diketahui bahwa seluruh item yang digunakan untuk mengukur variabel-variabel yang digunakan dalam penelitian ini mempunyai koofisien korelasi yang lebih besar dari r-Tabel. Standar Corrected item-total correlation $>0,300$. Hasil pengujian validitas ini menunjukkan bahwa pernyataan kuesioner dalam penelitian ini valid.

\section{Uji Reliabilitas}

Tabel 2. Hasil Uji Reliabilitas

\begin{tabular}{|l|c|c|}
\hline \multicolumn{1}{|c|}{ Variabel } & Cronbach Alpha & Keterangan \\
\hline Jejaring Wirausaha (X1) & .793 & Reliabel \\
\hline Pembelajaran Eksplorasi (X2) & .701 & Reliabel \\
\hline Kinerja UMKM (Y) & .714 & Reliabel \\
\hline
\end{tabular}

Sumber : Data diolah 2019

Berdasarkan tabel 2 Hasil pengujian penelitian menggunakan pengukuran ini dapat dikatakan reliabel pada Cronbach alpha $>0,600$. Hasil pengujian reliabilitas ini menunjukkan bahwa pernyataan kuesioner dalam penelitian ini reliabel.

\section{Analisis Statistik Deskriptif}

Analisis statistik Deskriptif digunakan untuk mengetahui gambaran atau deskripsi yang meliputi nilai rata-rata, serta nilai standar deviasi dari variabel dalam penelitian. Untuk penelitian ini sampel Pelaku UMKM Sebanyak 104 sampel.

Nilai rata-rata Kapabilitas Jejaring sebesar 9.97 dengan standar deviasi 2.849. Hasil ini menunjukkan nilai rata-rata kapabilitas jejaring perusahaan lebih besar dari pada standar deviasi. Hal ini menunjukkan hasil yang cukup baik.

Nilai rata-rata Pembelajaran Eksploratif UMKM sebesar 8.17 lebih besar dari pada standar deviasi sebesar 1.703. Hal ini juga menunjukan hasil yang baik. begitupun 
dengan nilai rata-rata Kinerja UMKM sebesar 24.53 lebih besar dari pada standar deviasi sebesar 2.849

\section{Uji Asumsi Klasik}

Uji Asumsi klasik dilakukan untuk memperoleh nilai penduga yang tidak bias dan efisien dari persamaan regresi dengan metode penafsiran kuadrat terkecil biasa (ordinary least square). Oleh karena itu, dalam pelaksanaan analisa data harus memenuhi asumsi klasik. Pengujian model regresi meliputi uji asumsi normalitas, multikoliniearitas, heteroksedasitas, dan autokorelasi. Uraian dari perhitungan pengujian asumsi model regresi dapat dijelaskan.

Untuk Pengujian normalitas data dalam penelitian ini menggunakan metode grafik dan uji Kolmogorof-Smirnov. Penelitian ini menggunakan dua variabel independen, maka pengujian normalitas data terbagi menjadi Data dari plot sisaan regresi yang dapat Untuk Pengujian Normalitas dapat disimpulkan bahwa sisaan regresi telah menyebar normal karena pola sisaan mendekati pola garis diagonal. Disamping itu dilakukan uji Kolmogorov- Smirnov diperoleh nilai signifikansi $\alpha=0.485>0.05$ (berdasarkan model regresi) artinya uji normalitas terpenuhi.

Untuk Uji Multikolinearitas pada penelitian ini dalam mendeteksi ada tidaknya multikolinieritas dapat dilihat dari Variance Inflation Faktor (VIF). Apabila nilai VIF > 10 maka menunjukkan adanya multikolinieritas. Apabila sebaliknya VIF $<10$ maka tidak terjadi multikolinieritas. Untuk Pengujian Multikolinearitas pada penelitian ini dapat disimpulkan bahwa masing-masing sesudah transformasi menunjukkan nilai VIF yang tidak lebih dari 10, maka tidak terjadi multikolinieritas.

Untuk Uji Heteroskedastisitas dalam penelitian ini dilakukan dengan melihat grafik plot. Indikasi terjadinya heterokedastisitas tampak pada pola tertentu yang dibentuk dalam plot. Apabila tidak terlihat adanya pola tertentu serta titik-titik penyebaran diatas dan dibawah sumbu $\mathrm{Y}=0$, maka tidak diindikasikan adanya heterokedastisitas. Pada penelitian ini plot diatas dapat dilihat bahwa titik-titik plot tidak membentuk pola tertentu dan cenderung menyebar disekitar sumbu $\mathrm{Y}=0$. Oleh karena itu dapat disimpulkan tidak terjadi heteroskedastisitas

Untuk Uji Aotukorelasi pada penelitian ini dilakukan dengan menguji ada tidaknya autokorelasi pada regresi variabel dependen dilakukan dengan memeriksa statistik Durbin- Watson (DW). Hasil Uji Autokorelasi Berdasarkan output SPSS Versi 20.0, Hasil uji Durbin-Watson menunjukan bahwa $1.719<1,823<2,281$. Dapat dilihat berdasarkan kriteria nomor 2 Jika $\mathrm{dU}<\mathrm{D}-\mathrm{W}<4-\mathrm{dU}$, kesimpulannya pada data tidak terdapat autokorelasi. Nilai uji D-W berada di daerah tidak ada autokorelasi, sehingga dapat disimpulkan bahwa persamaan regresi yang dihasilkan tidak terdapat gajala autokorelasi.

\section{Hasil Uji Hipotesis}

Selanjutnya untuk mengetahui apakah hipotesis yang diajukan dalam penelitian ini diterima atau ditolak maka akan dilakukan pengujian hipotesis dengan menggunakan uji t. Hasil pengujian hipotesis dijelaskan sebagai berikut: 
Tabel 3. Uji T

\begin{tabular}{|c|c|c|c|c|c|c|}
\hline \multicolumn{7}{|c|}{ Coefficients $^{\mathbf{a}}$} \\
\hline & \multirow{2}{*}{ Model } & \multicolumn{2}{|c|}{$\begin{array}{c}\text { Unstandardized } \\
\text { Coefficients }\end{array}$} & \multirow{2}{*}{$\begin{array}{c}\begin{array}{c}\text { Standardized } \\
\text { Coefficients }\end{array} \\
\text { Beta }\end{array}$} & \multirow[t]{2}{*}{$\mathbf{t}$} & \multirow[t]{2}{*}{ Sig. } \\
\hline & & B & Std. Error & & & \\
\hline \multirow{3}{*}{1} & (Constant) & 19.089 & 1.666 & & 11.460 & .000 \\
\hline & Jejaring Wirausaha & .391 & .104 & .349 & 3.762 & .000 \\
\hline & Pembelajaran Eksplorasi & .188 & .155 & .113 & 1.214 & .227 \\
\hline
\end{tabular}

Sumber: Data Diolah

\section{Pengujian Hipotesis Pertama.}

Hasil statistik uji t untuk variabel diperoleh nilai thitung sebesar 3.762 dengan nilai tabel sebesar 1,983 $(3.762<1,983)$ dengan nilai signifikansi sebesar 0,000 lebih kecil dari $0,05(0,000<0,05)$, dengan menggunakan $\alpha=5 \%: 2=2,5 \%$ (Uji dua sisi ) maka Hipotesis 1 diterima yang menyatakan bahwa "Jejaring Wirausaha berpengaruh terhadap kinerja UMKM di Kota Bima". Hal ini memberikan makna bahwa semakin tinggi atau semakin luas jejaring wirausaha yang dimiliki, maka kinerja UMKM semakin meningkat, artinya perusahaan yang mengelolah jejaring wirausaha secara maksimal mampu menciptakan value added dan competitive advantage yang akan bermuara terhadap peningkatan kineraj UMKM.

Hasil penelitian yang menemukan hubungan positive jejaring wirausaha terhadap kinerja UKM selaras dengan temuan (12) yang menyatakan bahwa informasi dan pengetahuan mempercepat pemahaman yang lebih baik mengenai pengembangan hubungan yang kuat dan fleksibel dengan para pelanggan, dan juga dengan anggotaanggota rantai pemasok yang lain. Hubungan yang lebih dekat dengan pemasok akan memberikan kontribusi yang cukup kuat terhadap kinerja perusahaan antara lain: efisiensi biaya, peningkatan kualitas, reabilitas dan pemenuhan kebutuhan input yang selalu tersedia setiap saat.

\section{Pengujian Hipotesis Kedua.}

Hasil statistik uji t untuk variabel diperoleh nilai thitung sebesar 1,214 dengan nilai tabel sebesar 1,983 $(1,214>1,983)$ dengan nilai signifikansi sebesar 0,227 lebih besar dari $0,05(0,227>0,05)$, dengan menggunakan $\alpha=5 \%: 2=2,5 \%$ (Uji dua sisi ) maka Hipotesis 1 ditolak yang menyatakan bahwa "Pembelajaran Eksplorasi tidak berpengaruh terhadap kinerja UMKM di Kota Bima". Hal ini tidak selaras dengan penelitian (14) yaitu dengan penelitian organisasi yang lebih menekankan pada tanggapan (responsiviness) dan mengelolah pengetahuan akan meningkatkan pembelajaan team, dan pada gilirannya, pembelajaran team mempengaruhi kinerja tugas dan kualitas hubungan interpersonal secara positif. Hal ini di manandakan para pelaku UMKM di kota Bima belum secara maksimal mendapatkan pembelajaran eksplorasi.

\section{Pengujian Hipotesis Kedua.}

Berdasarkan hasil penelitian yang telah dilakukan dapat diketahui variabel yang paling dominan dalam penelitian. Untuk menentukan variabel independen yang paling dominan terhadap kinerja UMKM, yaitu dengan melihat signifikansi yang nilainya terkecil. Variabel yang berpengaruh dominan terhadap kinerja UMKM adalah Jejaring Wirausaha dengan nilai signifikansi terkecil (0.000), 


\section{KESIMPULAN}

Kesimpulan dari penelitian ini adalah sebagai berikut

a. Jejaring Wirausaha berpengaruh terhadap kinerja UMKM di Kota Bima sedangkan Pembelajaran Eksplorasi tidak berpengaruh terhadap kinerja UMKM di Kota Bima

b. Bagi UMKM Kota Bima terutama hasil studi ini menjadi dukungan jejaring wirausaha yang kuat akan meningkatkan kinerja UMKM semakin meningkat, artinya perusahaan yang mengelolah jejaring wirausaha secara maksimal mampu menciptakan value added dan competitive advantage yang akan bermuara terhadap peningkatan kineraj UMKM

c. Sebagian besar UMKM di kota Bima dalam hal Pembelajaran Eksplorasi Pelaksanaan belum maksimal hal ini terbukti kurangnya pemahaman tentang pelatihan, kerja team sehingga para pelaku UMKM di kota Bima kurang pemahaman yang berkaitan dengan organisasi, dengan adanya organisasi akan lebih menekankan pada tanggapan (responsiviness) dan mengelolah pengetahuan akan meningkatkan pembelajaan team, dan pada gilirannya, pembelajaran team mempengaruhi kinerja tugas dan kualitas hubungan interpersonal secara positif. Hal ini di manandakan para pelaku UMKM di kota Bima belum secara maksimal mendapatkan pembelajaran eksplorasi.

\section{REFERENSI}

Aldrich, R., and Baker, T. 2000. Blinded by Cities Has There Been Progress in the Entrepreneurship Field in D. Sexton and R. Smilor (Eds), Entrpreneurship 2000. (pp.23-145. Chicago. Upstart Publishing Company.

Atmaja, L.S. 2009, Statistik untuk bisnis dan ekonomi. Yogyakarta: Andi

Batjargal, Bat. 2000. Effect of Networks on Entrepreneurial performance in A Transition Economy: The Case of Russia.,Havard University, Babson College.

Emory, C. W.,and Cooper, D. R . 2000. Business Research Methods, Homewood: Irwin. Ensley,M.D., Carland, L.C, Carland, J.W., and Bank, M (1999). Exploring the Existence of Entrepreneural Teams. International Journal of Management, $16,276-286$

Kirzner, I. 2003. Competition and Entrepreneurship. Chicago: University of Chicago Press.

Ireland, R. D., Hitt, M. A., and Sirmon, D. G. (2003). A Model of Strategic Entrepreneurship: The Construct and Its Dimensions. Journal of Management, 29 (6), 963-989. J386

Groen, A.J.2005 Davis. Knowledge Intensive Entrepreneurship in Networks: Towards A Multi-Level/Multi Dimensional Approach. Journal of Enterprising Culture, Vol.13, No 1, p 69-88

George, G., Wood, D. R. Jr, Khan, R .2001. Networking Strategy of Boards: Implicationn for Small and Medium-Sized Enterprises. Entrepreneurship-andRegionalDevelopment, 13(3), 269-285 
Marjono Susilawati Eni et Hariadin Taufan Guruh. 2015 Model Jejaringa Wirausaha, sebagai pendukung perekonomian perspektif keuangan dan non keuangan unit usaha kecil dan menengah Di semarang. jurnal Ilmiah MDP Vol 4 No 2.

Sugiyono . 2011, Metode Penelitian kuantitatif, kualitatif dan R\&D. Bandung:Alfabeta

Sugiyono. 2013. Metode Penelitian Pendidikan Pendekatan Kuantitatif, Kualitatif, dan R\&D. Bandung: Alfabeta

Terziovski, M 2003. The Relationship between networking practices and business excellence: a study o small to medium interprises (SMES). Measuring Business Excellence, vol 7. No.2 pg 78

Wiklund, J., and Shepherd, D. 2007, KnowledgeBased Resource, Entrepreneurial Orientation, and Performance of Small and Medium Sized Business. Strategic Management Journal, 24, 1307-1314

Zellmer-Bruhn, M. And Gibson, C. 2006, Multinational Organization Context: Implications for Team Learning and Performance, Academy of Management Journal, Vol.49 No.3, pp.501-1

Sakdiyah. 2017. Pengaruh Kompetensi, Lingkungan Makro dan Jejaring Usaha terhadap Kinerja Usaha Mikro Kecil dan Menengah (UMKM) Makanan di Kecamatan Kalinyaman Kabupaten Jepara, Vol.2, No.3.

Shinta Wahyu. 2017. Faktor-faktor yang Mempengaruhi Kinerja Usaha Mikro Kecil Menengah (UMKM) di Kota Batam. Jurnal Ekonomi. Vol 1. No. 2. 